\title{
Doctors commitment and long-term effectiveness for cost containment policies: lesson learned from biosimilar drugs
}

This article was published in the following Dove Press journal:

ClinicoEconomics and Outcomes Research

II November 2015

Number of times this article has been viewed

\section{Enrica Menditto' \\ Valentina Orlando' \\ Silvia Coretti ${ }^{2}$ \\ Daria Putignano' \\ Denise Fiorentino' \\ Matteo Ruggeri ${ }^{2}$}

'CIRFF, Center of Pharmacoeconomics, Federico II University of Naples, Naples, ${ }^{2}$ Postgraduate School of Health Economics and Management (ALTEMS), Università Cattolica del Sacro Cuore, School of Economics, Rome, Italy
Correspondence: Valentina Orlando CIRFF, Center of Pharmacoeconomics, Federico II University of Naples,

Via D Montesano 49, 80I3I Naples, Italy

$\mathrm{Tel}+39081678657$

Fax +39081678658

Email valentina.orlando@unina.it
Background: Agency is a pervasive feature of the health care market, with doctors acting as agents for both patients and the health care system. In a context of scarce resources, doctors are required to take opportunity cost into account when prescribing treatments, while cost containment policies cannot overlook their active role in determining health care resource allocation. This paper addresses this issue, investigating the effects of cost containment measures in the market of biosimilar drugs that represent a viable and cost-saving strategy for the reduction of health care expenditure. The analysis focuses on a particular region in Italy, where several timely policies to incentivize biosimilar prescribing were launched.

Methods: Drugs were identified by the anatomical therapeutic chemical classification system. Information about biosimilar drugs and their originator biological products was extracted from the IMS Health regional database. Drug consumption was expressed in terms of counting units, while expenditure was evaluated in Euro $(€)$. The market penetration of biosimilars was analyzed by year and quarterly.

Results: In the Campania region of Italy, the effects of cost containment policies, launched between 2009 and 2013, showed the prescription of biosimilars strongly increasing in 2010 until prescribing levels reached and exceeded the market share of the reference biological products in 2012. After a slight reduction, a plateau was observed at the beginning of 2013. At the same time, the use of the originator products had been decreasing until the first quarter of 2011. However, after a 1-year plateau, this trend was reversed, with a new increase in the consumption of the originators observed.

Conclusion: Results show that the cost containment policies, applied to cut health expenditure "to cure and not to care", did not produce the cultural change necessary to make these policies effective in the long run. Therefore, top-down policies for cost containment are not successful; rather, a bottom-up approach based on consensus among professionals should become the preferred option.

Keywords: cost containment policy, biosimilar drugs, health care expenditure, policy making

\section{Introduction}

Agency is a pervasive feature of the health care market: physicians treating patients, insurers purchasing services for their clients, and physicians providing care on behalf of private or public insurers. ${ }^{1}$ The doctor acts as a double agent, being both the patient's advocate and the gatekeeper of scarce health care resources. Moreover, the presence of a third-party payer might induce moral hazard whereby the physician, willing to please his patient and being aware that he/she will not pay for care, overlooks the treatment cost. ${ }^{2,3}$ Thus, the cost of medical care is strongly affected by the choice of the doctor. 
A number of scholars argue that, in publicly funded health care systems, the doctor should be considered as an agent of the whole community, since he/she ultimately determines the allocation of health care resources among patients. ${ }^{4}$

For these reasons, policy makers dealing with ever urgent cost containment measures undertake policies orienting physicians' prescribing behaviors to improve cost control. Nevertheless, the implementation of financial demand-side incentives might lead to ethically unacceptable situations, while mere recommendations not adequately supported by consensus among professionals may dramatically fail to modify nonscientific prescribing, especially where a managerial culture is lacking. ${ }^{5}$

Biotech drugs represent the main innovation of the last decade for the treatment of serious and life-threatening diseases. Those drugs approved for commercialization in the 1980s are now out of patent or will lose their monopoly protection shortly. This has paved the way for the development and the market launch of biosimilar drugs, whose active substance is similar but not identical to that of the reference product. ${ }^{6}$

Due to the complexity of their production and the legal barriers to the market, biosimilars imply less price erosion compared to generic drugs. From the theoretical point of view, this could be explained through a duopolistic market model, whereby originator and biosimilar compete on the price-sensitive portion of the market. As a matter of fact, unlike the generic drugs market, product differentiation relating to products' development determines the existence of a non-price-sensitive market segment, implying loyalty to the originator. ${ }^{7}$ Actually, the choice between originator and biosimilar is a clinical decision, and demand-side incentives ultimately determine biosimilars' consumption and the respective savings. The existing literature shows that appropriate information and involvement are key factors of success when attempting to modify the cost containment attitudes and practices of physicians. ${ }^{8-10}$ The market launch of a biosimilar, as determined by the European Medicines Agency (EMA), follows a centralized procedure requiring comparative analyses proving its similarity to the originator in terms of quality, safety, and efficacy. ${ }^{11}$ However, considerable cross-country differences in terms of utilization rates, pricing, and reimbursement policies exist. For instance, automatic substitution is forbidden in Spain, Greece, Sweden, Finland, and Germany, while in France, pharmacists can replace the biological product with a biosimilar of in naïve patients, even if the prescriber has explicitly prohibited the substitution. ${ }^{12-14}$
In Italy, the Italian Medicines Agency (AIFA) does not allow automatic substitution, but does recommend biosimilars for the treatment of naïve patients. Currently, eight of the 13 biosimilars approved by the EMA are on the Italian market: one biosimilar for somatropin, three biosimilars for epoetin (with the originator, epoetin alfa) and four biosimilar drugs for filgrastim. ${ }^{15}$

In November 2009, Campania was the first Italian region that issued directives to enhance the use of biosimilars, supporting their prescriptions for naïve patients. However, the regional directives did not follow from a wide involvement of physicians in the decision-making process and were not supported by adequate education and information programs meant to enhance consensus and commitment. ${ }^{16}$

\section{Aim of the study}

The present study aims to explore the impact of the regional cost containment policies implemented between 2009 and 2013 in Campania, Italy, to enhance the market penetration of biosimilar dugs, with a particular focus on epoetins. Starting with this case study, the present research investigates whether cost containment policies not supported by initiatives of involvement and education of physicians are effective in the long run.

\section{Methods}

This study compares biological and biosimilar drugs' utilization, within the Italian market, retrospectively. The analysis concerns all the biosimilar drugs marketed in Italy and their respective originator biological products (Table 1). Drugs were identified by the anatomical therapeutic chemical (ATC) classification system. Information about biosimilar drugs and their originator biological products was extracted from the IMS Health Regional Hospital Audit. ${ }^{17}$ It contains data about sales through the different distribution channels (retail, hospital, and distribution on behalf of local

Table I Biosimilar drugs marketed in Italy

\begin{tabular}{llll}
\hline Drugs & Originator & Biosimilar & $\begin{array}{l}\text { Date of biosimilar } \\
\text { marketing in Italy } \\
\text { (AIFA) }\end{array}$ \\
\hline Epoetin alfa & Eprex/erypro $^{\circledR}$ & Abseamed $^{\circledR}$ & April 2009 \\
& Eprex/erypro & Binocrit $^{\circledR}$ & October 2008 \\
Epoetin zeta & Eprex/erypro & Retacrit $^{\circledR}$ & February 2009 \\
Filgrastim & Neupogen ${ }^{\circledR}$ & Ratiograstim $^{\circledR}$ & April 2009 \\
& Neupogen & Tevagrastim $^{\circledR}$ & May 2010 \\
& Neupogen & Zarzio $^{\circledR}$ & January 2010 \\
& Neupogen & Nivegrastim $^{\circledR}$ & June 2010 \\
Somatropin & Genotropin & & Omnitrope \\
\end{tabular}

Abbreviation: AIFA, Italian Medicines Agency. 
health authorities). The analysis focuses on data from the Campania region in particular, and Italy in general, generated from drug sales concluded from 2009 to 2013.

Drug consumption was expressed in terms of counting units (CU), assimilated to a minimum divisible unit, while expenditure was evaluated in Euro $(€)$. The trends of expenditure and consumption were appraised using the compound annual growth rate (CAGR) for the considered time span. The CAGR was calculated by computing the nth root of the total growth rate expressed in percent. The market penetration of biosimilars was analyzed by year and quarterly. First, the trend of the consumption of biosimilars over years was observed and expressed as a percentage of the overall consumption of the biotech drugs. This stage of the analysis included all the biotech drugs for which at least one biosimilar is currently available. As epoetins represent the most prescribed categories among biosimilars in the study period, they represent the focus of the current analysis.

\section{Results}

\section{Trends in expenditure and consumption of biosimilars}

At a national level, a steady yet slight increase in the consumption of biosimilars was observed over time. As a matter of fact, while in 2009 the market penetration rate of biosimilars was $2.3 \%$ and $1.4 \%$, in 2013 , it raised to $25.3 \%$ and $23.9 \%$, in terms of consumption and expenditure, respectively.

Thus, the consumption of biosimilars increased from 67,998 CU to $930,859 \mathrm{CU}$ over 5 years, with a CAGR of 68.8 (Table 2). The expenditure on biosimilars, instead, increased from $€ 4$ million to more than $€ 92$ million, with a CAGR of 85.2 (Tables 3 and $\mathrm{S} 1$ ).

In the Campania region, the increase in the use of biosimilars was much faster. While in 2009 the penetration rate of biosimilars was $1.6 \%$ and $0.9 \%$, in 2013 , it was $35.9 \%$ and $31.4 \%$, in terms of consumption and expenditure, respectively. Thus, the consumption of biosimilars increased from 3,948 CU to $150,750 \mathrm{CU}$ over 5 years, with a CAGR of

Table 2 Consumption rates for biosimilar drugs in the Campania region vs Italy, from 2009 to 2013

\begin{tabular}{|c|c|c|c|c|c|c|}
\hline \multirow{2}{*}{$\begin{array}{l}\text { Biosimilar } \\
\text { drugs }\end{array}$} & \multicolumn{5}{|c|}{ Counting units (\%) } & \multirow[t]{2}{*}{ CAGR } \\
\hline & 2009 & 2010 & 2011 & 2012 & 2013 & \\
\hline Campania & 3,948 & 64,703 & 125,860 & 158,056 & 150,750 & 107.2 \\
\hline region & $(1.6)^{*}$ & $(20.6)^{*}$ & $(35.5)^{*}$ & $(40.1)^{*}$ & $(35.9)^{*}$ & \\
\hline \multirow[t]{2}{*}{ Italy } & 67,998 & 188,126 & 410,397 & 698,601 & 930,859 & 68.8 \\
\hline & $(2.3)^{*}$ & $(5.7)^{*}$ & $(11.9)^{*}$ & $(19.7)^{*}$ & $(25.3)^{*}$ & \\
\hline
\end{tabular}

Note: *Percentage of biological drugs consumed. Abbreviation: CAGR, compound annual growth rate.
Table 3 Expenditure in Euro (€) on biosimilar drugs, 2009-20I3, in the Campania region vs Italy

\begin{tabular}{|c|c|c|c|c|c|c|}
\hline \multirow{2}{*}{$\begin{array}{l}\text { Biosimilar } \\
\text { drugs }\end{array}$} & \multicolumn{5}{|c|}{$€$ in millions (\%) } & \multirow[t]{2}{*}{ CAGR } \\
\hline & 2009 & 2010 & 2011 & 2012 & 2013 & \\
\hline Campania & 0.258 & 6,498 & 12,099 & 15,448 & $|5,28|$ & 126.2 \\
\hline region & $(0.9)^{*}$ & $(18.3)^{*}$ & $(30.5)^{*}$ & $(35.3)^{*}$ & $(31.4)^{*}$ & \\
\hline \multirow[t]{2}{*}{ Italy } & 4,241 & 14,837 & 37,560 & 67,498 & 92,423 & 85.2 \\
\hline & $(1.4)^{*}$ & $(4.3)^{*}$ & $(10.4)^{*}$ & $(18.0)^{*}$ & $(23.9)^{*}$ & \\
\hline
\end{tabular}

Note: *Percentage of biological drugs consumed.

Abbreviation: CAGR, compound annual growth rate.

107.2 (Table 2). In addition, the expenditure on biosimilars, increased from $€ 257,000$ to more than $€ 15$ million, with a CAGR of 126.2 (Tables 3 and S2).

\section{Trends in epoetin consumption}

In the case of epoetin, the Campania was the first Italian region to encourage the prescription of biosimilars through regional legislation, with the purpose of rationalizing health care expenditure. More specifically, the aim of the decrees was to incentivize prescribers to prefer biosimilars over the originators, in case of equal therapeutic indications and the same administration regimen; any deviation from this approach needed to be justified, and a monitoring system was established..$^{18-21}$ However, no reward/penalty system was introduced. Table 4 summarizes the cost containment policies launched between 2009 and 2013 in Campania.

Table 4 Pharmaceutical cost containment policies developed in the Campania region to incentivize the use of biosimilars

\begin{tabular}{|c|c|c|}
\hline Measure & Date & Con \\
\hline $\begin{array}{l}\text { Decree } \\
\text { number } 15^{18}\end{array}$ & $\begin{array}{l}\text { November 30, } \\
2009\end{array}$ & $\begin{array}{l}\text { All prescribers when prescribing } \\
\text { biological treatments must prefer } \\
\text { biosimilars with equal therapeutic } \\
\text { indications and administration regimen, } \\
\text { with an average savings target of at least } \\
40 \% \text { per therapy }\end{array}$ \\
\hline $\begin{array}{l}\text { Decree } \\
\text { number } 44^{19}\end{array}$ & $\begin{array}{l}\text { July 14, } \\
2010\end{array}$ & $\begin{array}{l}\text { Reiterates what was stated in decree } \\
\text { number I } 5 \text { and specifies that the } \\
\text { obligation of prescribing biosimilar drugs } \\
\text { for the same therapeutic indications } \\
\text { refers to "naïve patients" }\end{array}$ \\
\hline $\begin{array}{l}\text { Decree } \\
\text { number } 34^{20}\end{array}$ & $\begin{array}{l}\text { March 20, } \\
2012\end{array}$ & $\begin{array}{l}\text { Reiterates what was stated in } \\
\text { decree number } 15 \text { and specifies that } \\
\text { in the treatment of naive patients, the } \\
\text { biosimilar drug with the lowest cost } \\
\text { should be preferred }\end{array}$ \\
\hline $\begin{array}{l}\text { Decree } \\
\text { number } 27^{21}\end{array}$ & $\begin{array}{l}\text { March I5, } \\
2013\end{array}$ & $\begin{array}{l}\text { The biosimilar drug with the lowest cost } \\
\text { per therapy should be considered as the } \\
\text { first treatment option in naïve patients } \\
\text { for all the therapeutic indications unless } \\
\text { in case of negative clinician's judgment }\end{array}$ \\
\hline
\end{tabular}

Note: Data modified from references. ${ }^{18-21}$ 
The effect of the decree number $15 / 2009^{18}$ was immediate, with the prescription of biosimilars strongly increasing in the first quarter of 2010. This trend kept growing as a result of regional measures implemented between 2010 and 2012 (decree numbers 44/2010 and 34/2012). ${ }^{19,20}$ From Figure $1 \mathrm{~A}$, depicting temporal trends, it is also clear that by April 2012, the consumption of biosimilar epoetins reached and exceeded the market share of the reference biological products; peak consumption was reached in the third quarter of 2012, and after a slight reduction, a plateau was observed at the beginning of 2013. At the same time, the use of the originator products had been decreasing until the first quarter of 2011 ( $\Delta \%$ 2011-2010, -29.7\%). However, after a 1-year plateau, this trend was reversed, with a new increase in the consumption of the originators ( $\Delta \%$ 2011-2010, $+14.5 \%)$ observed.

A starkly different trend was observed at a national level. In fact, in Italy as a whole, growth in biosimilar consumption close to $0 \%$ was observed in 2009 . However, since the first quarter of 2010, there was a steady and continuous increase in biosimilar consumption, not followed by a decrease in the reference biological products' consumption.
This increase in biosimilar epoetins persisted until the end of 2013 (Figure 1B).

\section{Discussion}

In the health care market, the doctor plays the role of double agent, determining the demands of patients on the health care system and acting as a gatekeeper of the system. Moreover, in publicly funded health care systems characterized by scarcity of resources, the doctor could also be considered as an agent of the whole community, because any prescribed medical treatment has an opportunity cost in terms of benefits forgone elsewhere. ${ }^{7}$

In modern health care systems, policy makers often implement measures to constrain doctors' discretion in order to achieve cost containment. ${ }^{8-10}$ However, these measures are effective only in combination with adequate incentives for professionals. Th present study addresses this issue, with particular focus on the Italian experience with the introduction of biosimilar drugs. In detail, the aim of this study was to show to what extent regional pharmaceutical planning has had a positive effect on the penetration of biosimilars into the market of biological products.
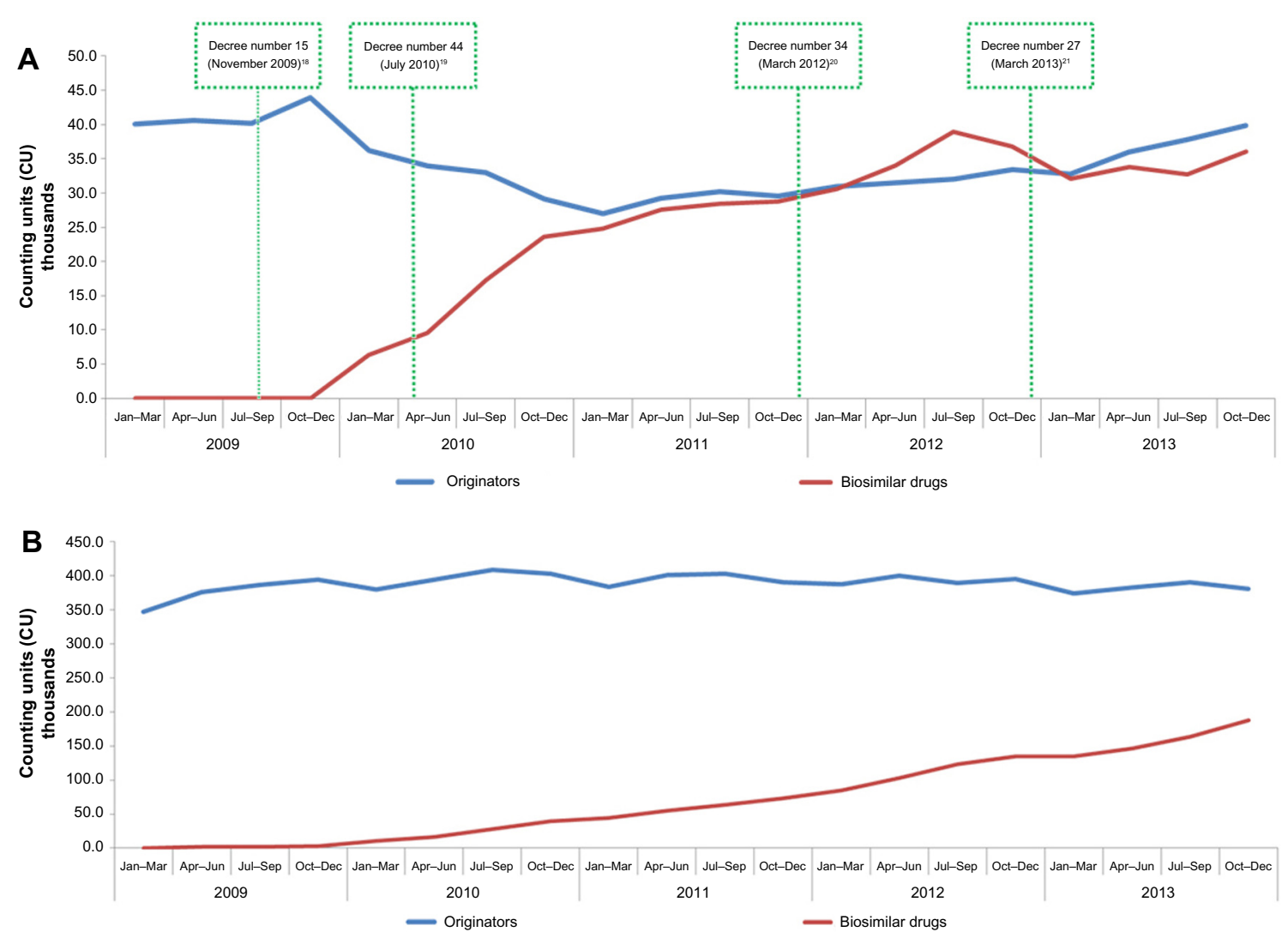

Figure I Consumption of epoetin from 2009 to 2013 in the Campania region (A), and in Italy (B). Note: Data modified from references. ${ }^{18-21}$ 
The advantage of biosimilars is that they might be a viable and cost-saving alternative to originator drugs, resulting in a reduction of health care expenditure for the third-party payer. In Europe, the estimated biosimilar-related savings for the years 2007-2020 range between $€ 11.8$ billion and $€ 33.4$ billion. Estimates for biosimilar-related savings over the same time period in Italy range between $€ 0.7$ billion and $€ 3.2$ billion. $^{22}$

Campania was the first region in Italy to define in advance a rather restrictive and explicit directive that immediately resulted in a high level of market penetration of biosimilars. As a matter of fact, in 2011, the penetration of biosimilars in the Campania region, in terms of volume (CU), was already approximately $35 \%$ and exceeded by far the national percentage of only $12 \%$. However, while in Campania such a market penetration percentage peaked in the third quarter of 2012 and remained steady at the beginning of 2013, the national penetration rate still exhibits a slow but constant growth. ${ }^{16}$

This phenomenon is probably due to the cost containment policies applied in Campania that, in the field of biosimilars, started well in advance compared to other regions in Italy. These cost containment policies yielded an immediate effect in the short term that has not persisted over time. This point deserves particular attention from policy makers. Indeed, the cost containment policy, applied with the sole purpose of cutting health expenditure to cure and not to care, did not produce the cultural change necessary to make these policies effective in the long term. ${ }^{16}$

Specialized literature explains physicians' reluctance to accept biosimilars with a lack of proper information on their economic advantages or with the presence of conflicting incentives. For instance, since biosimilar drugs are prescribed for serious and life-threatening illnesses, most often, a patient's co-payment is limited or zero; this situation might induce moral hazard whereby the physician, being aware that the patient will not pay for the treatment, overlooks the treatment cost. ${ }^{23}$

Moreover, empirical studies show that top-down policies to involve physicians in cost containment are not successful and that enhancing transparent and independent information flow and communication would encourage physicians to act in the interests of patients, foster trust, and make physicians aware of the great importance of equal treatment for all patients. ${ }^{24-26}$ This point also raises the question of how innovation could be successfully introduced into clinical practice.

A previous study by Godman et $\mathrm{al}^{25}$ focused on policies meant to enhance the efficiency of prescribing behaviors though the promotion of generic drugs, and reached similar conclusions. In detail, Godman et $\mathrm{al}^{27}$ found that multiple and intensive demand-side measures are needed to enhance the pre- scribing of generic drugs such as proton pump inhibitors and statins. Multiple measures resulted in considerable efficiency in savings in some European countries, when products were considered as therapeutically similar at appropriate doses in all or nearly all patients. However, there are certain classes of drug for which treatment should be tailored to the individual patient. In these circumstances, it is difficult for health authorities to issue multiple demand-side measures to affect changes in physicians' prescribing habits, and therefore, health authorities need to wait until more drugs become available as generics to realize appreciable savings. ${ }^{27}$

We feel that the main strength of the present study lies in its ability to provide an overview of the development of the biosimilars market in Italy, both at local and national levels in recent years, emphasizing the potential effects of the latest legal interventions to foster the prescription of biosimilar products and to ultimately achieve cost containment. On the other hand, the main limitation of the current study is that, for the current analysis, we had no access to individual patient-level data, which would have allowed the full investigation of indications of use and switches from biosimilar to biological drugs. The lack of patient-level data also prevented us from formulating further hypotheses on other possible explanations for market trends that could have affected biosimilar/originator use when the substitution trend was reversed. Nonetheless, our data are useful to explore the dynamics that are currently characterizing the market penetration of biosimilar drugs within a specific context.

\section{Conclusion}

The lesson learnt from the case of biosimilars is that adequate conditions should be established before technology uptake in order to make innovation effective and affordable. In order to achieve change, several equally important interventions are necessary. First, prescribers should be provided with adequate information and education programs to create consensus; second, integration among clinicians through peer review processes should be encouraged; third, a system of constant monitoring of prescriptions and of drugs' effectiveness and safety should be established with the chance for professionals to give feedback; and finally, financial and nonfinancial incentives could be useful to align the system's and the professional's objectives.

\section{Acknowledgment}

The authors thank Maurizio Maggini from IMS Health, S.p.A., Milan, Italy, for assistance in data acquisition. 


\section{Author contributions}

EM conceived and designed the study. VO analyzed the data and wrote the manuscript. SC, EM, and MR critically reviewed the manuscript for important intellectual content and contributed to the discussion. DP and DF did extraction and data analysis. EM and VO interpreted the data. MR provided study supervision. All authors contributed toward data analysis, drafting and critically revising the paper, gave final approval of the version to be published, and agree to be accountable for all aspects of the work.

\section{Disclosure}

No funding was provided for this work. The authors report no conflicts of interest in this work.

\section{References}

1. Dranove D, White WD. Agency and the organization of health care delivery. Inquiry. 1987;24:405-415.

2. Pauly MV. Medicare drug coverage and moral hazard. Health Aff (Millwood). 2004;23(1):113-122.

3. Coulson NE, Stuart BC. Insurance choice and the demand for prescription drugs. Southern Econ J. 1995;1146-1157.

4. Lundin D. Moral hazard in physician prescription behavior. J Health Econ. 2000;19(5):639-662.

5. Eisenberg JM, Williams SV. Cost containment and changing physicians' practice behavior. Can the fox learn to guard the chicken coop? JAMA. 1981;246(19):2195-2201.

6. Blackstone EA, Joseph PF. The economics of biosimilars. Am Health Drug Benefits. 2013;6(8):469-478.

7. Chauhan D, Towse A, Mestre-Ferrandiz J, editors. The market for biosimilars: evolution and policy options. OHE Briefing, No. 45, October 2008. Social Science Research Network. Available from: http://papers. ssrn.com/sol3/papers.cfm?abstract_id=2641004. Accessed May 13, 2015.

8. Rettig RA. Medical innovation duels cost containment. Health Aff (Millwood). 1994;13(3):7-27.

9. Greene HL, Goldberg RJ, Beattie H, Russo AR, Ellison RC, Dalen JE. Physician attitudes toward cost containment: the missing piece of the puzzle. Arch Intern Med. 1989;149(9):1966-1968.

10. Axt-Adam P, van der Wouden JC, van der Does E. Influencing behavior of physicians ordering laboratory tests: a literature study. Med Care. 1993;31:784-794.

11. Committee for Medicinal Products for Human Use. Guideline on Similar Biological Medicinal Products. London: European Medicines Agency; 2014. Available from: http://www.ema.europa.eu/docs/en_GB/ document_library/Scientific_guideline/2014/10/WC500176768.pdf. Accessed February 19, 2015.
12. Schück S, Texiers N. Biosimilars: the French policy. Int J Risk Saf Med. 2009;21:41-45.

13. Mellstedt $\mathrm{H}$, Niederwieser D, Ludwig $\mathrm{H}$. The challenge of biosimilars. Ann Oncol. 2008;19(3):411-419.

14. Niederwieser D, Schmitz S. Biosimilar agents in oncology/haematology: from approval to practice. Eur J Haematol. 2011;86(4):277-288.

15. Agenzia Italiana del Farmaco. AIFA. AIFA position paper. I farmaci biosimilari [Biosimilars]. Available at: http:/www.agenziafarmaco. gov.it/sites/default/files/AIFA_POSITION_PAPER_FARMACI_ BIOSIMILARI.pdf. Accessed May 13, 2015. Italian.

16. Ingrasciotta $Y$, Giorgianni F, Bolcato J, et al. How much are biosimilars used in clinical practice? A retrospective Italian population-based study of erythropoiesis-stimulating agents in the years 2009-2013. BioDrugs. 2015;29(4):275-284.

17. IMS Health [homepage on the internet]. Available from: http://www. imshealth.com/portal/site/imshealth. Accessed May 13, 2015.

18. Decreto n. 15 del 30 novembre 2009. [Decree number 15, November 30, 2009]. Available from: http://www.aslna3sud.it/regione/DECRETO_15_ DELIBERAZIONI_DEL_COMMISSARIO_AD_ACTA. Accessed May 13, 2015. Italian.

19. Decreto commisariale n. 44 del 14/07/2010. [Decree number 44 , July 14, 2010]. Available from: http://www.aslcaserta.it/portale/Portals/0/doc_ pub/2012/ATTIREGIONE/dca_44_Misure\%20di\%20controllo\%20 spesa\%20farmaceutica.pdf. Accessed May 13, 2015. Italian.

20. Decreto n. 34 del 20.03.2012. [Decree number 34, March 20, 2012]. Available from: http://www.aslcaserta.it/portale/Portals/0/doc_ pub/2012/ATTIREGIONE/34_Farmaci\%20biosimilari.pdf. Accessed May 13, 2015. Italian.

21. Decreto n. 27 del 15.03.2013. [Decree number 27, March 15, 2012]. Available from: http://www.arsan.campania.it/documents/10157/59773/ DCA_27_13.pdf. Accessed May 13, 2015. Italian.

22. Haustein R, de Millas C, Höer A, Häussler B. Saving money in the European healthcare systems with biosimilars. Generics Biosimilars Initiat J. 2012;1(3-4):120-126.

23. Farfan-Portet MI, Gerkens S, Lepage-Nefkens I, Vinck I, Hulstaert F. Are biosimilars the next tool to guarantee cost-containment for pharmaceutical expenditures? Eur J Health Econ. 2014;15(3):223-228.

24. Schwartz RK, Soumerai SB, Avorn J. Physician motivations for nonscientific drug prescribing. Soc Sci Med. 1989;28(6):577-582.

25. Hogerzeil HV. Promoting rational prescribing: an international perspective. Br J Clin Pharmacol. 1995;39(1):1-6.

26. Weise M, Bielsky MC, De Smet K, et al. Biosimilars: what clinicians should know. Blood. 2012;120(26):5111-5117.

27. Godman B, Wettermark B, van Woerkom M, et al. Multiple policies to enhance prescribing efficiency for established medicines in Europe with a particular focus on demand-side measures: findings and future implications. Front Pharmacol. 2014;17(5):106. 


\section{Supplementary materials}

Table SI Expenditure in Euro $(€)$ on biosimilar drugs and biological drugs, 2009-2013, Italy

\begin{tabular}{llllll}
\hline Italy & \multicolumn{6}{l}{$\boldsymbol{\epsilon}$ in millions (\%) } \\
\cline { 2 - 6 } & $\mathbf{2 0 0 9}$ & $\mathbf{2 0 ~ I 0}$ & $\mathbf{2 0 I ~ I}$ & $\mathbf{2 0 I 2}$ & $\mathbf{2 0 I 3}$ \\
\hline Biosimilar drugs & $4,24 \mathrm{I}$ & 14,837 & 37,560 & 67,498 & 92,423 \\
& $(1.4)^{*}$ & $(4.3)^{*}$ & $(10.4)^{*}$ & $(18.0)^{*}$ & $(23.9)^{*}$ \\
Biological drugs & 302,573 & $332,15 \mathrm{I}$ & 336,959 & 327,456 & 323,915
\end{tabular}

Note: *Percentage of biological drugs consumed.
Table S2 Expenditure in Euro $(€)$ on biosimilar drugs and biological drugs, 2009-2013, Campania region

\begin{tabular}{llllll}
\hline Campania region & \multicolumn{6}{c}{ in millions (\%) } \\
\cline { 2 - 6 } & $\mathbf{2 0 0 9}$ & $\mathbf{2 0 1 0}$ & $\mathbf{2 0 1 1}$ & $\mathbf{2 0 1 2}$ & $\mathbf{2 0 1 3}$ \\
\hline Biosimilar drugs & 0.258 & 6,498 & 12,099 & 15,448 & 15,281 \\
& $(0.9)^{*}$ & $(18.3)^{*}$ & $(30.5)^{*}$ & $(35.3)^{*}$ & $(31.4)^{*}$ \\
Biological drugs & 27,053 & 34,846 & 38,118 & 41,944 & 45,576 \\
\hline
\end{tabular}

Note: *Percentage of biological drugs consumed.

\section{Publish your work in this journal}

ClinicoEconomics \& Outcomes Research is an international, peerreviewed open-access journal focusing on Health Technology Assessment, Pharmacoeconomics and Outcomes Research in the areas of diagnosis, medical devices, and clinical, surgical and pharmacological intervention. The economic impact of health policy and health systems organization also constitute important areas of coverage. The manuscript management system is completely online and includes a very quick and fair peer-review system, which is all easy to use. Visit http://www.dovepress.com/testimonials.php to read real quotes from published authors.

\footnotetext{
Submit your manuscript here: http://www.dovepress.com/clinicoeconomics-and-outcomes-research-journal
} 